\section{Iatrogenic Ulcers of the Small Intestine}

SIR,-We should like to report another possible case of ileal ulceration and perforation in a patient receiving enteric-coated potassium-chloride tablets but not chlorothiazide.

In June, 1964, a woman aged 58 was diagnosed as having pemphigus vulgaris. This proved difficult to control and necessitated an initial suppressive dose of $210 \mathrm{mg}$. prednisolone and 120 units corticotrophin gel daily. Control was achieved and the steroids were gradually withdrawn during the following four months without recurrence of the permphigus. Her serum potassium fell steadily during treatment despite constant administration of enteric-coated potassium-chloride tablets $1 \mathrm{~g}$. twice daily increasing on 19 August to $2 \mathrm{~g}$. three times a day. It was suspected, and later confirmed, that she was not taking all her potassium and she discharged herself on 26 August with a serum potassium of only $2.7 \mathrm{mEq} / 1$. She was warned of the possible consequences and by 2 September her potassium was 5.1 rising to $5.5 \mathrm{mEq} / 1$., suggesting that she was now taking the full dose of potassium chloride-that is $6 \mathrm{~g}$. daily.

At about this time she began to complain of vague lower abdominal pain associated with tenderness and diarrhoea. Her E.S.R., which had varied from 25 to $45 \mathrm{~mm}$. (Westergren), rose to $85 \mathrm{~mm}$./hr. and has since fluctuated between 44 and $116 \mathrm{~mm}$. On 1 November the pulse rate rose suddenly to 120 and she was mildly shocked. A gastrointestinal perforation was suspected and she consented to admission but refused operation. The haemoglobin fell to $58 \%$ and occult bloods were positive. Triamcinolone was finally discontinued on 22 November but potassium chloride was continued. She gradually improved until on 10 December 1964 a barium enema revealed a fistula between the ileum and pelvic colon. A few diverticula were present in the colon. At no time during her illness were thiazide-type diuretics administered. -We are, etc.,

\section{K. D. Crow.}

A. G. FREEMAN

G. C. Griffiths.

J. A. M. AGRR.

E. E. Evans.

Princess Margaret Hospital,

Swindon, Wilts.

\section{Rapid Estimation of Blood Glucose}

SiR,-Like Dr. Vincent Marks and Mr. A. Dawson (30 January, p. 293) we have been satisfied with Dextrostix when used for bedside estimations of blood glucose on diabetic children undergoing stabilization. When this technique is used on the newborn, however, there are important qualifications, as the following case history illustrates:

A female infant, mature by date, weighed $5 \mathrm{lb} .12 \mathrm{oz}$. at birth which was rapid and unassisted. She cried at once and accepted small feeds (sweetened water followed by dilute milk) during the first 48 hours. At 48 hours she had a sudden prolnnged cyanotic attack and was rushed to hospital. On arrival she was deeply cyanosed and jactitating, but was successfully resuscitated. A blood-sugar estimation was carried out using a heel-prick sample by the Dextrostix method. The foot was cyanosed and cool, but bled freely: the blood appeared dark and concentrated. No colour change occurred on the Dextrostix paper, indicating blood-glucose concentration of less than $40 \mathrm{mg}$.I $100 \mathrm{ml}$. The umbilical vein was catheterized at once and a venous sample obtained: an infusion of $25 \%$ glucose solution was then given. By the Folin and $\mathbf{W u}$ method the venous bloodsugar level before the infusion was found to have been $80 \mathrm{mg} . / 100 \mathrm{ml}$. Meanwhile a further infusion of $20 \%$ fructose snlution had been given. After 15 minutes the Dextrostix test was again applied to blond from annther puncture of the same heel; again no colour change was observed, using strips from two separate boxes. Immediately afterwards blood drawn from the umbilical catheter gave the maximum colour change on a Dextrostix, and by the Folin and Wu method a value of $800 \mathrm{mg} . / 100 \mathrm{ml}$. was obtained.

We conclude that when there is stagnation of the peripheral circulation, as in the cyanosed limbs of an ailing neonate, the glucose level in heel-prick blood may fall to a level quite unrepresentative of that in the central circulation. Therefore, to rely on heel-prick samples for the diagnosis of hypoglycaemia in neonates may prove seriously misleading.-We are, etc.,

\section{Malcolm MacGregor.} RONALD ROBINSON.

Warwick Hospital, Warwick.

\section{Ischaemic Heart Disease and Pregnancy}

SIR,-Dr. M. F. Oliver in his letter (30 January, p. 315) on oral contraceptives and coronary thrombosis states that "from all the millions of pregnancies only some 30 cases of ischaemic heart disease have now been recorded." Although the incidence of coronary-artery disease associated with pregnancy would seem to be very low, Mendelson ${ }^{1}$ lists 45 cases and refers to another 12 instances of anginal syndrome. Seventeen of the 45 were reported in the five years up to 1959 , perhaps due to an increased certainty in modern diagnostic methods. Further cases have been reported since and Pfaffenschlager ${ }^{2}$ reported a case of myocardial infarction in a 21-year-old gravida.

I am grateful to Mr. F. Selby Tait for permission to report a further case of effort angina in pregnancy which was recently under his care.

The patient aged 41 years, para $3+0$, a suillbirth at 30 weeks in 1949, and normal deliveries at term in 1950 and $1952(3,380 \mathrm{~g}$. and 3,235 g.), was first seen in September 1963, ten weeks after her last menstrual period with a history of angina of effort. For two months she had experienced precordial pain on walking, which forced her to stop and was relieved by rest, but recurred on further exertion. There was no history or signs of previous rheumatic fever. The weight was $69 \mathrm{~kg}$., the blood-pressure 130/70 $\mathrm{mm}$. of mercury, the haemoglobin concentration 12.7 g. $/ 100 \mathrm{ml}$., and the Wassermann reaction negative. The resting electrocardiograph showed confirmatory changes in the S.T. segment; the radiographic cardiovascular silhouette was within normal limits.

The pregnancy progressed normally, the anginal symptoms, which persisted only until the 25 th week, were relieved by glyceryl trinitrate. The blood-pressure ranged between $90 / 60$ and $130 / 70 \mathrm{~mm}$. of mercury. There was no oedema and the total weight gain was $10.4 \mathrm{~kg}$.

She was admitted to hospital on 1 May 1964, two days after the expected date of confinement. The onset of labour was spontaneous six days later. After a first stage of $3 \frac{1}{3}$ hours, and 30 minutes in the second stage, she was delivered as a prophylaxis by low-forceps extraction under pudendal-block anaesthesia of a healthy living female infant weighing $3,725 \mathrm{~g}$. The third stage was normal. Lactation was suppressed. She was discharged home after an uneventful early puerperium on the ninth day. When she attended the post-natal clinic six weeks postpartum she was tired and said she had experienced further chest pain. She was referred for family-planning advice.
While agreeing that ischaemic heart disease is uncommon in pregnancy $I$ feel that there must be other unrecorded cases and that this serves to emphasize the rarity.-I am, etc.,

H. Oliphant Nicholson.

Queen Elizabeth Hospital Birmingham.

\section{REPERENCES}

1 Mendelson, C. L., Cardiac Disease in Pregnancy. 1960. F. Davis, Philadelphia.

Pfaffenschlager, F., Wien. Klin. Wschr., 1964, $76,297$.

\section{Oral Contraceptives and Breast Cancer}

SiR,-Dr. B. A. Stoll (3 October, p. 875) in a reply to the letter of Mr. J. J. Shipman (5 September, p. 629) writes that the experimental studies of Huggins stand against Shipman's supposition that the commonly used oral contraceptives may predispose toward the development of breast cancer or accelerate its growth when present.

Huggins $^{2}$ used massive doses of progesterone and oestrogen and found the efficacy of his regimen dependent on a certain ratio of oestradiol-17 $\beta$ to progesterone $(20 \mathrm{mg}$. of the former to $4 \mu \mathrm{g}$. of the latter daily for 30 days). In the first place it cannot be said that the relative doses of progesterone and oestrogen in the oral contraceptive preparations are similarly balanced, nor do they approach the massive level required for demonstration of the effect in Huggins's study. Furthermore, it has been shown clearly that norethindrone and norethynodrel have a strong inherent oestrogenicity. At least in the case of those oral contraceptive agents including these compounds as the progestational component the balance of progesterone versus oestrogen action may strongly favour oestrogenic effects. ${ }^{2}$ The importance of dose levels in determining the response of metastatic breast-cancer growth in post-menopausal women is critical. Low doses may accelerate, large doses suppress.

Finally, it is clearly undesirable for medical men to equate the physiologic actions of the synthetic 19 nor-steroids and the various substituted pregnane derivatives with those of progesterone itself. Semantic sins of this sort are apt to extort a rather high cost against accuracy in thought, interpretation, and therapeutic planning.-I am, etc.,

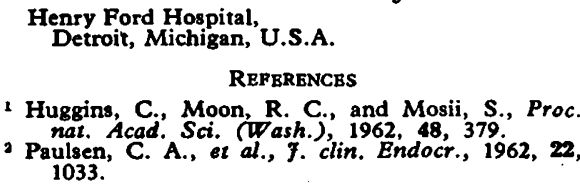
Henry Ford Hospital, REFBRENCBS

1 Huggins, C., Moon, R. C., and Mosii, S., Proc Paulsen, C. A., et al., J.) clin. Endocr., 1962, 22 1033. Michael J. Brennan.

\section{Oral Contraceptives and Coronary Thrombosis}

SIR,-Dr. J. H. Naysmith (23 January, p. 250) asks if there is an increased risk of coronary thrombosis occurring in women taking the pill, and if so are we justified in subjecting our patients to this risk. In the case which he describes Dr. Naysmith does not state whether necropsy revealed atheromatous change in the coronary arteries. Dr. Flora M. Hartveit (2 January, p. 60) describes an incident of fatal coronary thrombosis in a woman taking oral contraceptives and where detailed necropsy failed to show the presence 